\title{
Towards Knowledge Networking ${ }^{1}$
}

Andreas Seufert, Georg von Krogh, Andrea Back

\begin{abstract}
„Most important, in an age of rapidly proliferating knowledge, the central domain is a social network that absorbs, creates, transforms, buys, sells, and communicates knowledge. Its stronghold is the knowledge embedded in a dense web of social, economic, contractual, and administrative relationships“ (Badaracco 1991, pp. 13-14).
\end{abstract}

Keywords: Networks, Knowledge Management, Framework Knowledge Networks, Facilitating Conditions, Knowledge Work Processes, Knowledge Network Architecture

\begin{abstract}
:
In this article we describe an integrated view on knowledge management and networking being a very powerful combination for the future of knowledge management. We start by giving an overview of the increasing importance of networks in the modern economy. Subsequently, we conceptualize a Network perspective on knowledge management. Therefore we firstly give a theoretical foundation on networks, and secondly explain the interdependences between networks and knowledge management. These reflection lead to the development of a framework for knowledge networking, where we distinguish between a micro-perspective and a macro-perspective. Finally, we develop a framework for knowledge networking which can be used as a basis in order to structure and reveal interdependences. We conclude by giving some implications for management and future research.
\end{abstract}

\section{Introduction}

Organizations are changing more and more from well-structured and manageable systems into interwoven network systems with blurred boundaries. „Genuine sharing of authorities takes place. Firms are neither fully independent nor is one wholly dependent upon the other. They do not lose their legal identities; they retain their own culture and management structure and can pursue their own strategies. But they do reduce their autonomy, share decision making,

\footnotetext{
${ }^{1}$ We are very grateful for comments and support from C. Miskin and our colleagues in the "KnowledgeSource" at the University of St. Gallen, especially the core team of the Competence Center Knowledge Networks, K. Gysin, M. Köhne, J. Raimann and S. Vassiliadis.
} 
interconnect their organization structure, manage jointly some activities or operations, and open their company culture to outside influences" (Badacarro 1988, p. 73). Assuming this evolution to be the trend for future organizations, we must presumably - from a knowledge management perspective - perceive managing knowledge creation and transfer as taking place in the context of a network rather than view it from a traditional organizational perspective. Therefore ,the focus shifts from products and firms as units of analysis to people, organizations, and the social processes that bind together in ongoing relationships" (Webster 1992, p. 10). Since we believe this network perspective to be crucial for the future of knowledge management, we conceptualize an integrated view of what we call knowledge networking, develop a framework, and conclude by giving the implications for management. In the following, we start by showing that the trend towards networked organizations is not restricted to some few companies or industries, in order to emphasize the need for a network perspective on managing knowledge.

\section{Increasing importance of Networks}

Taking a very wide perspective, one could assume the work of Fayol in 1916 to be the origin of research on network structures. In recent years the discussion of team-based network structures in management literature has been influenced above all by the research of Drucker (1989), Savage (1990), Keen (1991) and Nolan/Pollock/Ware (1988). Today, hardly any industry remains unaffected by the evolution of network-like relationships within and between firms. Without making any claim to comprehensiveness, we believe the following examples will serve to show the increasing importance of networks in the modern economy.

In Manufacturing Industries, the automotive industry is a representative example of the evolution towards the networked organization not only in a temporal respect, but also with regard to its macroeconomic and over-all social importance. In the course of the reduction of manufacturing depth, more and more parts and components from stand-alone suppliers are linked into a system of industrial partnerships (Lodge/Walton 1989, Morris/Imrie 1991, Barreyre 1988). One might think of the networking that takes place between manufacturers and subcontractors, manufacturers and trader organizations, and even between manufacturers themselves (Sabel/ Kern/ Herrigel 1991).

Even if the biotechnological industry is still in its infancy, there are a great number of networked organizations to be found there. „The locus of innovation should be thought of as a network of inter-organizational relations. Biotechnology is probably an extreme case of this 
tendency“ (Arora/Gambarella 1990, p. 374). Weisenfeld/Chakrabari (1990) found this general assumption confirmed in an investigation of the technology - and marketing strategies of 96 US- American and 17 German Biotechnology companies. Of especially great importance are bilateral co-operation and license agreements used for the acquisition of external technology. However, such cooperation with other firms does not as yet obviate the need for internal R \& D activities in this line (Arora/Gambarella 1990).

Over the last 30 years, publishers have started to outsource first the printing, then the graphical and artistic organization, and finally the text and/or data acquisition and parts of their positions as instructors. Marketing is mostly carried out via a network of stand-alone traders. Today, the usual core functions of a book publisher comprise mainly procurement and distribution. Large publishers have established sections as special publishers with less bureaucratic structures and may carry out their functions in a loosely connected network as legally and economically stand-alone units (Powell 1990).

In Service Industries, e.g. insurance firms work more and more with stand-alone agencies and brokers instead of having their own employees to do the field-work. The proportion of employees to stand-alone agencies decreased from 60:40 in 1980 to 45:55 in 1985 (Mayer/Paasch 1987). As regards the European market in general, one may expect a further stabilization of the market position of company representatives and brokers. The trend to be observed towards the externalization of work in the insurance industry will assuredly be increased by the progress of interorganizational information systems as well as by intensive efforts to strengthen the organizational and personal ties between stand-alone agencies and insurance companies (Sydow/ Windeler/ Krebs/ Loose/ van Well 1995).

Taking the systemic character of most hardware and software products and the market structure into account, there is hardly any industry in which there are more strategic alliances and networks already established than in the Electronics branch. The Telecommunications industry, for example, is, in its interlinkage, very similar to the international co-operation relationships to be found in the automotive industry (Pisano/Russo/Teece 1988; Lamb 1990). The retail trade began many years ago to externalize even its most basic original functions (e.g., transportation, rack-care, shop-in the-shop principle) and to cooperate instead with firms which supply it with these services (Müller-Hagedorn 1990, p. 454). Owing to current outsourcing, more and more employees are being dismissed into a new "dependent independence" (Mayer/Paasch 1990), to work as propagandists or temporary workers. The entire variety of vertical distribution systems, from agency contracts via appointed retailer 
systems up to franchises can be seen as a form of close coordination between co-operating business networks.

Since even large transportation firms are linked into strategic networks, forwarding agents do indeed play a dependent role on the one hand, but on the other, they are of significant importance to the business. These forwarding combines are made up of small and very small forwarding firms and other service providers (Mayer/Paasch 1990; Paasch 1990) and thus form a network within the network. Additionally, small and medium-size forwarding agents cross-link their activities to mobilize an effective market-presence capable of meeting demand arising anywhere in Europe.

\section{Networks and Knowledge Management}

In order to be able to conceptualize a framework for knowledge networking, we will firstly give a theoretical foundation on networks, and secondly explain the interdependences between networks and knowledge management.

\subsection{Theoretical foundation on Networks}

The term "networks" can be interpreted as those between individuals, groups, or organizations, as well as between collectives of organizations. In all these cases, the "network" construct demands that description and analysis does not concentrate only on a section of the relationships existing between the network participants and network relationships, but also comprehends the network in its entirety. According to a frequently quoted definition, a social network can be seen as: „a specific set of linkages among a defined set of actors, with the additional property that the characteristics of these linkages as a whole may be used to interpret the social behavior of the actors involved" (Mitchel 1969, p. 2; Tichy/Tushman/Fombrun 1979, p. 507; Alba 1982, p. 40; Lincoln 1982). Consequently, the term "network" designates a social relationship between actors. Actors in a social network can be persons, groups, but also collectives of organizations, communities or even societies ${ }^{2}$.

The relationships evolving between actors can be categorized according to contents (e.g., products or services, information, emotions), form (e.g., duration and closeness of the relationship) and intensity (e.g., communication-frequency). Typically, network relationships 
are characterized by a multiple mixture concerning form and contents, i.e., the relationships between actors are of various forms, which may consist of diverse contents to be exchanged. The form and intensity of the relationships establishes the network structure (Burt 1979; Alba 1982, pp. 42-43). Besides formalized networks, the literature stresses the importance of informal networks as the results of and prerequisites for decision-making processes in organizations (Morgan 1986, pp. 173-174; Sandner 1990, pp. 147-151), the importance of the interconnection of organization-wide actions (Probst 1987; Luhmann 1988), and the influence of managers' positions in the internal network on their cognition and information-processing (Walker 1985).

Networks are structural as well as cultural (Krebs/Rock 1994, p. 329). The relationships between the actors are founded upon personnel-organizational or technical-organizational interconnections on a long-term basis. The relationships between network members can be understood as deriving from their autonomy and interdependence, the coexistence of cooperation and competition as well as reciprocity and stability. Since the boundaries of networks are difficult to determine, we may speak of blurred boundaries which are constructed socially by the network members. By taking this perspective, we shift the focus from the consideration and protection of the boundaries of a firm to the management of and care for relationships. Reich (1991a, p. 81), depicts a firm as ,...a facade, behind which teems an array of decentralized groups and subgroups continuously contracting with similar diffuse working units all over the world.“

Some authors look upon networks as a third form of organization to be distinguished (Powell 1990). However, in most cases they are conceptualized as a hybrid form of organization between market and hierarchy (Thorelli 1986; Siebert 1991; Sydow 1992), because they contain elements of both forms. Following the neoclassical market theory, markets coordinate discrete transactions exclusively on the basis of prices, which contain all relevant information. Typically, market relationships are short-term and competitive. On the other hand, hierarchy coordinates activities on the basis of instructions given to a limited number of organization members. Ideally, these instructions replace for every market-based coordination. Coordination occurs by contract and comprises discrete transactions as well as blurred

\footnotetext{
${ }^{2}$ Cognitive psychology, it should be noted here, examines a human being as a cognitive network. It regards an individual as a network of constructs (Kelly 1955). Since the studies of Bavelas (1950) on communication in groups, the latter have become conceptualized as social networks.
} 
interactions (like for example helping people to speed up their career). In contrast to marketrelationships, hierarchical ones are ideally long-term and co-operative.

Networks may result on the one hand through internalization, that is to say, an intensification of cooperation, or externalization in the form of a limited functional outsourcing achieved by loosening hierarchical coordination mechanisms. With regard to different functional areas, both types, which entail more than just a modification of divisions of labor, can be pursued in parallel within an enterprise. Moreover, internalization and externalization can occur not only horizontally, i.e., on the same level, but also vertically with regard to actors on different levels of the value chain, e.g. suppliers or customers.

\subsection{Integrating Network and Knowledge Management Perspectives}

Knowledge is increasingly recognized by modern organizations as their most important source of lasting competitive advantage. However, the key to obtaining long-term competitive advantage is not to be found in the administration of existing knowledge, but in the ability constantly to generate new knowledge, and to move on to new products and services (von Krogh/ Venzin 1996). Rather than viewing firms as devices for processing information, making decisions, and solving problems, one should realize that they are based increasingly on knowledge-seeking and knowledge-creation.

In order to conceptualize the integration of networks and knowledge management, we will outline on the one hand our knowledge-networking approach, which differs from traditional knowledge management concepts, and on the other illustrate certain selected benefits of knowledge-networking.

Concerning the integration of networking and knowledge management, we believe at least two main aspects to be crucial. First, knowledge management should comprise an holistic view of knowledge, that is to say, the integration of explicit and tacit knowledge. Furthermore, knowledge management should take an holistic view on where or rather how knowledge is being created and transferred.

Knowledge is often thought of as an objective commodity which is transferable independently of person and context. On the basis of this mental model, people often try to solve problems by improving the information flow with the intensive use of modern technologies such as Intranet-based yellow pages, knowledge maps, or information Warehouses. The potential of innovative technologies for the mastery and distribution of explicit knowledge, i.e., knowledge which is pinned down verbally in writing or electronically and can therefore be 
communicated and distributed, is undisputed. However, what is required is an integrated approach which includes both explicit and tacit knowledge. Since tacit knowledge is deeply rooted in personal experiences, subjective insights, values and feelings, it can hardly be completely communicated and shared. Tacit knowledge can be conceptualized as possessing a technical and a cognitive dimension. Whereas the technical dimension contains informal, personal abilities and skills, often designated as "know-how", the cognitive dimension includes our mental model influenced by our beliefs, values and convictions (Nonaka/ Takeuchi 1995). For this reason, we are convinced that in order to make effective use of knowledge, a network must be built up in which the knowledge and experience of employees are available. What is of prime importance is that creation- and sharing-processes are encouraged, not just the accumulation of data as in a data-warehouse (see also Seufert 1997). Although working, learning and innovation complement each other, they are nowadays still strictly separated in many firms as a result of their disparate mental models (Brown/Duguid 1991). Working is traditionally seen as the production and delivery of products or services. Formal operating instructions and workflows are designed to execute this as efficiently as possible (Hammer/Champy 1993; Davenport 1993). As attention is focused upon the efficiency with which the task is carried out, this field is frequently resistant to modifications. Learning is regarded explicitly as the absorption of new knowledge, whereas this potential is in fact used most inadequately to increase the firm's ability to innovate. The underlying pattern of the learning processes is often responsible for this. On the one hand, these processes simply focus on individual employees' acquisition of knowledge instead of inducing them to learn how to learn, and how to inter-link areas of knowledge (Seufert/ Seufert 1998b; Seufert/ Seufert 1999); on the other hand, they obstruct the transfer of new knowledge into workingskills by using training-methods confined too narrowly to the acquisition of pre-defined theoretical concepts. Finally, innovation is often associated with revolutionary proposals developed, for example, in the Research Laboratory or other specialized departments. This form of innovation admittedly constitutes an important part of change in general, but is just one extreme within a continuum of innovations. They can also take the form of mere renewals and improvements in daily business, e.g., process improvements.

Focusing on explicit knowledge only, as well as taking a too narrow view of work, learning and innovation areas, involve the danger of erecting barriers of various kinds: functional and hierarchical, for instance; barriers to customers, suppliers and co-operation partners; or mental barriers which impede the generation, transfer and application of new knowledge. These not only hinder the short-term flow of knowledge but in the long term prove detrimental to a 
company's innovation- and learning-ability. Based on integrated knowledge management, networking knowledge may deliver a conceptual framework for rethinking a knowledgemanagement model. In this case, knowledge barriers should be overcome by "networking", and knowledge islands should be cross-linked in order to stimulate the evolution, dissemination and application of knowledge.

The integration of networking into knowledge management yields great benefits. The openness and richness of networks are believed to foster a fertile environment for the creation of entirely new knowledge, while also accelerating the innovation rate. Powell/Koput/SmithDoerr (1996) demonstrated a ladder effect, in which firms with experienced partners competed more effectively in high-speed learning races. Rather than trying to monopolize the returns from innovative activity and forming exclusive partnerships with only a narrow selection of organizations, successful firms positioned themselves as the hubs at the center of overlapping networks, stimulating rewarding research collaborations among the various partner-organizations. Reliance on networks has potentially transformative effects on all participants. Those positioned in a network of external relations adopt more administrative innovations, and do so earlier. The presence of a dense network of collaborative ties may even alter participants' views on competition. Inside a densely connected field, organizations must adjust to a novel perspective in which it is no longer necessary to have exclusive ownership of an asset in order to profit from it. Moreover, since a competitor on one project may become a partner on another, the playing field resembles less a horse-race and more a rugby match, in which players frequently change the color of their jerseys.

In sum, regardless of whether networking is driven by gaining access to new knowledge, or by creating and transferring knowledge, connectivity to a network and competence at managing networks have become key drivers of a new business logic. A framework for knowledge networking could be helpful in order to give it structure and reveal interdependences.

\section{A Framework for Knowledge Networking}

In the following we will firstly give a definition of what we call knowledge networking and will secondly describe a framework of knowledge networking. 


\subsection{Definition}

We use the term "Knowledge Networking" to signify a number of people, resources and relationships among them, who are assembled in order to accumulate and use knowledge primarily by means of knowledge creation and transfer processes, for the purpose of creating value. Concerning the development of knowledge networks, we distinguish between emergent and intentional ones. Intentional knowledge networks are seen as networks that are built up from scratch, whereas emergent knowledge networks already exist but have to be cultivated in order to become high-performing. In this way, a network may evolve whose participants share a common language, and a common set of values and objectives. This (social) network is backed up and transformed by information- and communication technology. As this network of knowledge-resources is continuously being augmented by knowledge gained from learning situations, a Knowledge Network should be regarded as a dynamic structure rather than as a static institution.

\subsection{Description}

The Framework of Knowledge Networks comprises the following components: Actors individuals, groups, organizations; relationships between actors, which can be categorized by form, content and intensity; resources which may be used by actors within their relationships, and institutional properties, including structural and cultural dimensions such as control mechanisms, standard operating-procedures, norms and rules, communication patterns, etc.

These components can be perceived from either a static or a dynamic point of view. From a micro perspective, we conceptualize knowledge networks on the following three buildingblocks (see figure 1). 


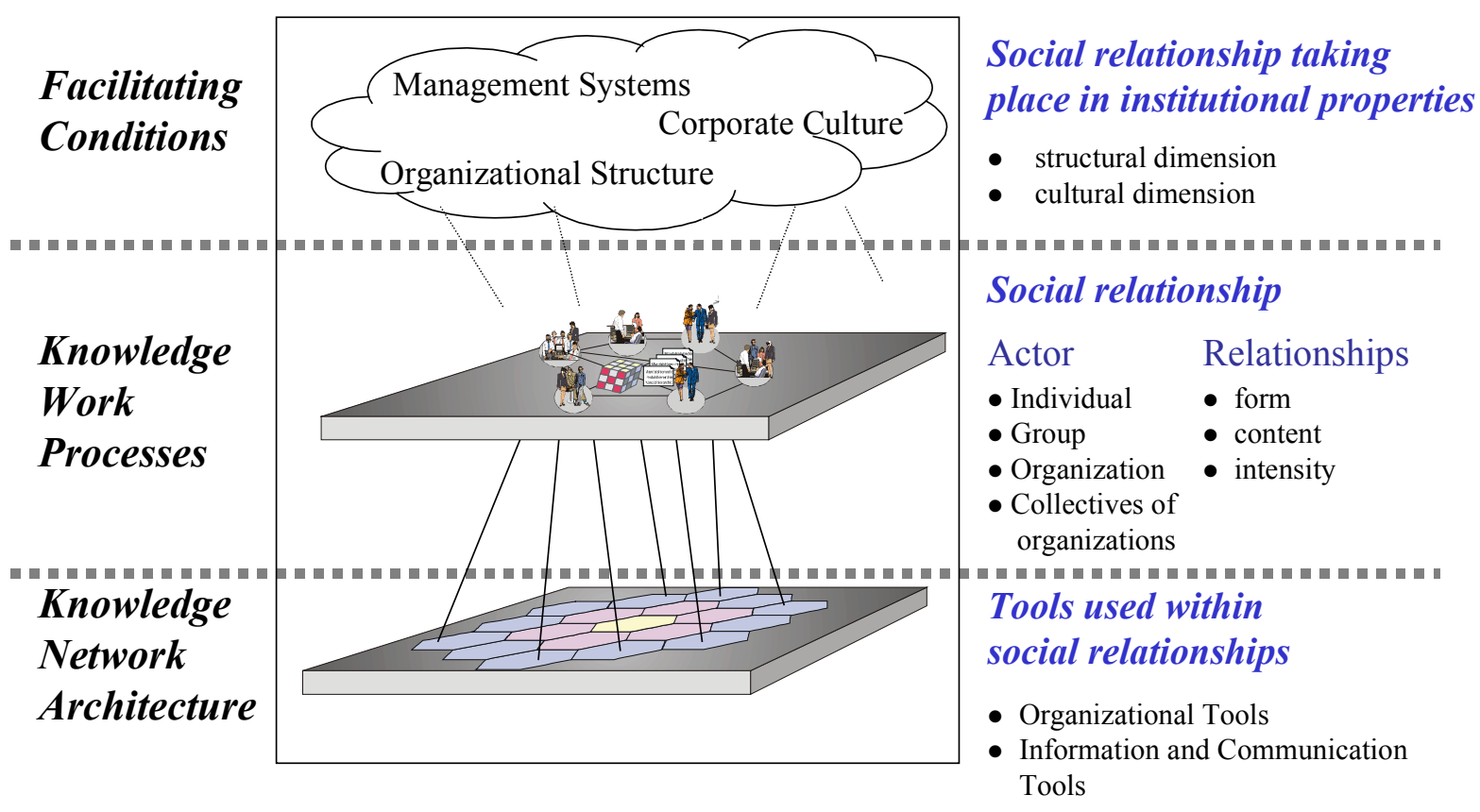

Figure 1 Framework Knowledge Networks - a micro perspective

- Facilitating Conditions comprise the network's internal structural and cultural dimensions in which knowledge work processes take place. Therefore, they define the enabling or inhibiting environment for knowledge creation and transfer. The organizational structure, management systems or network culture may be termed "categories to be taken into account". Care, for instance, as conceptualized by von Krogh (1998) is, as a part of the network structure, crucial for knowledge creation. According to whether there is a high- or low-care environment, knowledge creation and transfer processes will differ considerably. Care involves helping behavior among people, lenience in judgement of new ideas, and an active attitude to understand others.

- Knowledge Work Processes comprise social interaction and communication processes on an individual and group level, which can advance for knowledge evolution to an organizational and interorganizational level. Following Nonaka (Nonaka 1991; Nonaka/ Konno 1998) these processes can be conceptualized as a knowledge spiral i.e., as a dynamic transformation-process between explicit and tacit knowledge on the different layers (see figure 2). 


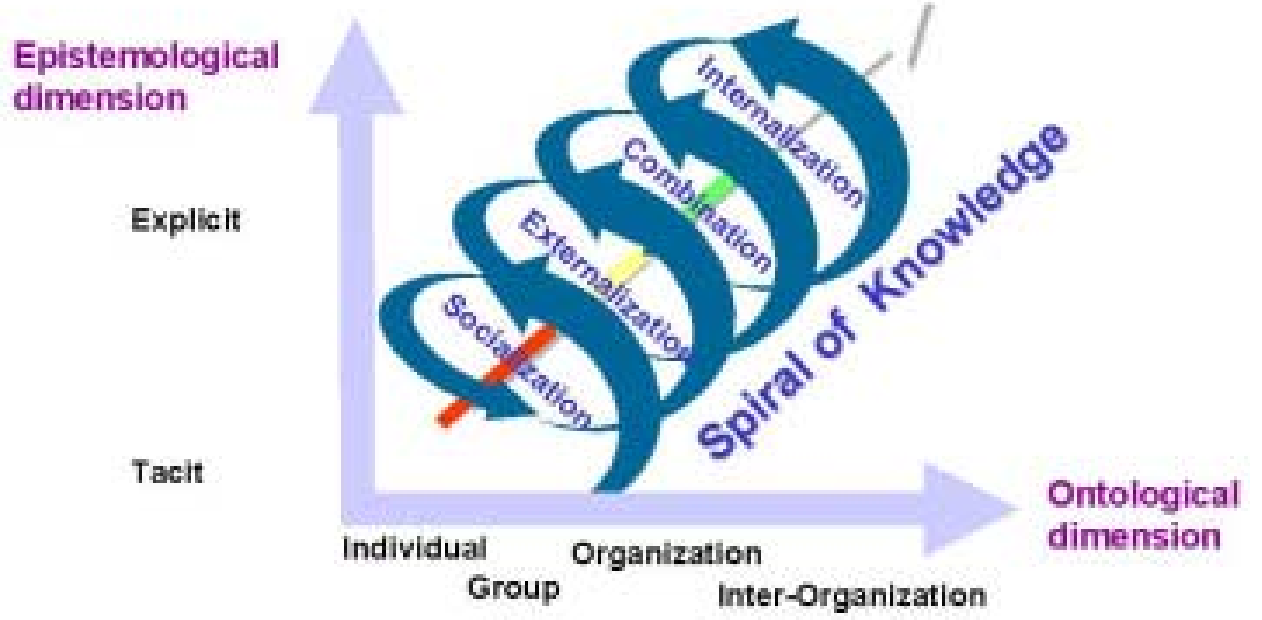

Figure 2 Knowledge Work Processes as Knowledge Spiral

Sozialization comprises the exchange of tacit knowledge between individuals in order to convey personal knowledge and experience. Joint experience result in new shared implicit knowledge, such as common values or technical skills. In practice, this could mean, for instance, gaining intuitive and personal knowledge through physical proximity and attaining direct communication with customers or a supplier. Externalization describes transformation processes. On the one hand, this means the conversion of implicit into explicit knowledge, and on the other, the exchange of knowledge between individuals and a group. Since implicit knowledge is difficult to express, the conversion process is often supported by the use of metaphors, analogies, language rich in imagery, or stories, as well as visualization aids, like models, diagrams or prototypes. In order to stage a constructive discussion and reach creative conclusions, a deductive or inductive mode of argumentation is also very important. The transformation of explicit knowledge into more complex and more systematized explicit knowledge represents the stage combination (recently Nonaka renamed this stage Systematization, Nonaka 1999). It is necessary to combine different fields of explicit knowledge with each other and make new knowledge available on an organization-wide basis. The systematization and refinement increases the practical value of existing knowledge and increases its transferability to all organizational units. Internalization comprises the conversion of organization-wide, explicit knowledge into the implicit knowledge of the individual. This requires from the individual that she/he should be able to recognize personally relevant knowledge within the organization. Continuous learning and the gathering of one's own experience through "learning-by-doing" may support employees in these internalization 
processes. In this way both capabilities and skills ("know-how") as well as firm visions and guidelines may be internalized and therefore shared throughout the whole company. This tacit knowledge and the experience gained on an individual level can be shared again through socialization-processes between individuals, so that the knowledge spiral may be set in motion once more.

When cultivating the relationships that are the basis for these knowledge work processes we will take into account the transformational effects that information and communication technology can have for the form and intensity of communication, cooperation and coordination within Nonaka`s four knowledge spiral process categories. His concept of "Ba" (Nonaka/ Konno 1998) is a step into that direction that is not yet a comprehensive view of how new media effect these knowledge work processes.

- Knowledge Network Architecture, finally, comprises the tool-set used within social relationships. These tools include organizational tools, e.g., roles like the knowledge activists (von Krogh/ Nonaka/ Ichijo 1997) as well as information and communication tools, e.g., the groupware-enabled data warehouse concept (Seufert 1997) used to enable and improve knowledge work processes (Nonaka/ Reinmoeller/ Senoo 1998).

This architecture is not only a collection of modular tools. In the form of "solution frameworks" we want to link architectural designs that are a combination of ICT and organizational tools and methods with the knowledge work processes level. Especially development in groupware-infrastructure technology and research have a close affinity to communication and cooperation processes in knowledge creation (Back 1995) that we study here.

Following the network definition earlier in this article knowledge networks may be understood as social networks between knowledge actors, in order to allow the creation and transfer of knowledge on an individual-, group, organization and inter hierarchical level. From the point of view of a dynamic knowledge management model we consider the following aspects to be of great importance (Seufert/Seufert 1998a):

- Interconnect the different levels and areas of knowledge:

Knowledge results from networking previous knowledge with new knowledge. Therefore it is essential to enable the networking between individual knowledge types (explicit and implicit), the networking between different levels (e.g. individual, group, organization) and areas of knowledge (e.g., customer knowledge, R\&D knowledge ).

- Interconnect knowledge work processes and knowledge network architecture: 
Knowledge creation and transfer (von Krogh/Köhne 1998) can occur at different real (e.g. in the office, with the customer), virtual (e.g. distributed team rooms) or mental (e.g. common values, ideas, ideals) "places". They can establish themselves in the form of formal or informal networks. Since knowledge occurs more and more in different timezones and different physical places, the knowledge of the potential and capability to use modern informations and communications technologies seems to be a critical success factor. In addition to these formal networks informal networks or relationships are a crucial component for the knowledge ecology (Krackhardt/ Hanson 1997).

- Interconnect knowledge work processes and facilitating conditions:

In order to be able to develop their optimal knowledge creation/ transfer processes and facilitating conditions must be cross-linked with each other. On the one hand these processes are to be synchronized with the environment and the corporate culture within those occur. On the other hand, the companies should actively develop and maintain facilitating conditions in order to allow and support an efficient and effective knowledge creation and transfer.

Although we look upon knowledge networks as a separate layer rather than a new kind of organizational unit, we do finally have to take into account from a macro-perspective interdependences between the knowledge network itself and the surrounding organizational unit. In order to develop a high-performance knowledge network they have to be synchronized by facilitating conditions, which we divided into structural (e.g. organizational structure, management systems) and cultural (e.g. corporate culture, organizational behavior) dimensions. One might think of the organizational unit as an organ receiver, the knowledge network as a life-saving organ which is to be transplanted, and the facilitating conditions as actions taken to prevent the organ's rejection by the body.

Contemplating Knowledge Networks in a long-term rather than a short-term perspective, one might hypothesize a positive relation between knowledge networks and organizational development. Adapting Orlikowski (1992) and Giddens (1991) we conceptualize the interplay between structure and action for knowledge networks and the organizational unit from a dynamic point of view (see figure 3). As a consequence of knowledge networking firms will have the opportunity to develop themselves into truly networked organizations. 


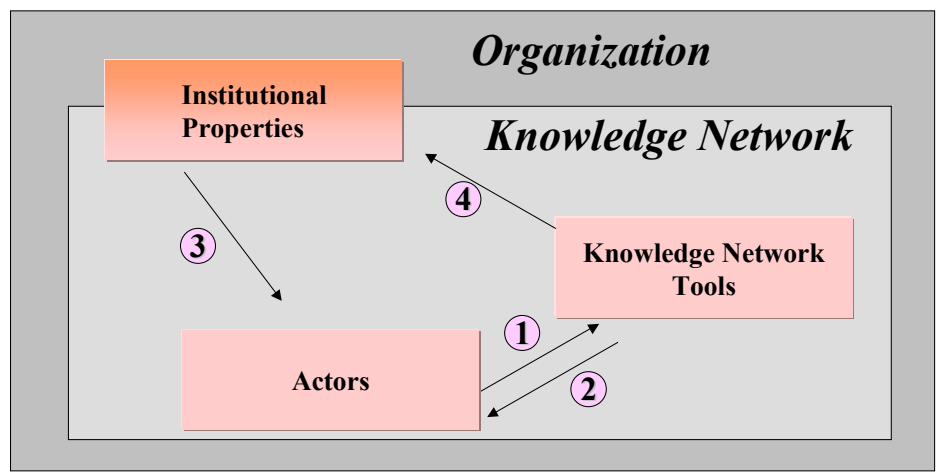

\begin{tabular}{|c|c|c|}
\hline Arrow & Type of influence & Nature of influence \\
\hline 1 & $\begin{array}{l}\text { Knowledge Networks tools as a } \\
\text { product of human action. }\end{array}$ & $\begin{array}{l}\text { Knowledge Networks tools are an outcome of human interaction and } \\
\text { communications processes. }\end{array}$ \\
\hline 2 & $\begin{array}{l}\text { Knowledge Networks tools as a } \\
\text { medium of human action. }\end{array}$ & ks tool \\
\hline 3 & $\begin{array}{l}\text { Facilitating Conditions of } \\
\text { Interaction with Knowledge } \\
\text { Networks tools }\end{array}$ & $\begin{array}{l}\text { Institutional Properties influence humans in their interaction with } \\
\text { knowledge network tools; e.g. management systems, culture. }\end{array}$ \\
\hline 4 & $\begin{array}{l}\text { Institutional Consequences of } \\
\text { Interaction with Knowledge } \\
\text { Network tools }\end{array}$ & $\begin{array}{l}\text { Interaction with Knowledge Network tools influences the } \\
\text { institutional properties of the knowledge network through re- } \\
\text { inforcing or transforming structures of domination and legitimation. } \\
\text { Since the institutional properties of the knowledge network and the } \\
\text { surrounding organization are interconnected and have to } \\
\text { synchronized, changes inside the knowledge networks may affect } \\
\text { the organization in it totality. }\end{array}$ \\
\hline
\end{tabular}

Figure 3 Framework Knowledge Networks - a macro perspective

\section{Implications for Management}

On being appointed „Knowledge (Network) Manager“, your responsibility will rely on putting theoretical frameworks into practice. It is our research team's ambition to transform the work of the Competence Center Knowledge Networks into pragmatic, action-oriented research results. We want to provide the Knowledge Network manager with a handbook that comprises methods and guidelines on how to "manage" knowledge-creation and -transfer in the context of networking. This handbook is now about to take shape. The following statements are therefore not yet an outline of this manual. On the one hand, they briefly summarize our understanding of knowledge networks and the respective framework. On the other hand, they are propositions for essential methods and guidelines to yet be proven in our future work. 
Knowledge Network Management denotes a proactive, systematic approach to the planning and design of intentional, formalized networks for knowledge creation and transfer, and the establishment of conditions to cultivate emergent, informal networks. This includes the identification of existing knowledge networks, widening their scope, guiding them towards high performance, and transferring best practices to other application contexts. This is in contrast to some narrow, purely ICT-oriented views of Knowledge Management, which solely focus on the administration of explicit knowledge. In discussions on specifying knowledge networks in more detail, it became obvious that a Knowledge (Network) Manager needs a list of criteria to analyze and position such high performing networks within a conceptual framework of the:

- types of knowledge networks (characteristics),

stages within the life-cycle of knowledge networks

in order to benchmark existing or projected networks against best practices.

Managers need guidelines to specify the potentially reciprocal links between strategic business goals and those of their knowledge network agenda. The advancement of knowledge creation and transfer in a specific organization will generate a number of suggested knowledge network projects. How to select and prioritize these projects to match them to planned resources, such as in portfolio techniques, is an important requirement for the handbook.

Establishing and cultivating knowledge networks entails the definition of essential new roles to be adopted by the knowledge network manager and others. Especially the case study research in the competence center will be the source of understanding which role layouts work and can be suggested in the knowledge network context.

Being able to meet interdisciplinary and cross-functional challenges must be a matter-ofcourse for knowledge network management. It is indispensable, for instance, to establish bridges to human resources/ personnel development and corporate education/ training, as the design of learning programs and processes needs to be oriented towards knowledge creation and transfer. Knowledge activists or knowledge workshop facilitators are examples for such rather new functions. Furthermore the linkage between knowledge network management and ICT strategy needs to be improved. You can still find the misconception of the role of ICT in knowledge management as merely a set of tools to support traditional processes and as just a means of storing data and documents in "data/information/knowledge-bases". Technical overenthusiasm or over-kill is detrimental when it becomes an impediment to social processes. On the other hand, underestimating the value of or ignoring ICT can lead to non-exploitation of 
opportunities for "rethinking" processes and structures in knowledge networks for the competitive advantage of the organization. ICT related tools and solution frameworks need the reliable infrastructure.

Our research will progress along the lines of network thinking. The research agenda covers some of the mentioned management challenges, as well as other studies which will be outlined in future articles and books. Our belief is that knowledge management an networking will mutually benefit from a stronger integration. 


\section{References}

Alba, R. D. (1982): Taking stock of network analysis: A decade`s results. In: Bacharach, S. B. (Ed.): Research in the sociology of organizations. JAI. Greenwich. Conneticut, pp. 39-74.

Arora, A./ Gambarella, A. (1990): Complementary and external linkages: The strategies of the firms in biotechnology. In: Journal of Industrial Economics, 38, pp. 361-379.

Back, A. (1995): Entwicklungen im Markt und in Anwendungsfeldern von Groupware. In: Informatik/ Informatique, 6, pp. 4-7.

Badaracco, J. L. (1988): Changing forms of the corporation. In: Meyer, J. R./ Gustafson, J. M. (Ed.) The U. S. business corporation - An institution in transition. Ballinger. Cambridge, pp. 67-91.

Badaracco, J. L. (1991): The Knowledge Link - How Firms Compete Through Strategic Alliances. Harvard Business School Press. Boston.

Barreyre. P. Y. (1988): The concept of ,impartition“ policies: A different approach to vertical integration strategies. In: Strategic Management Journal, 9, pp. 507-520.

Bavelas, A. (1950): Communication patterns in task oriented groups. In: Journal of the Acoustical Society, 22, S. 271-282.

Brown, J. S./ Duguid, P. (1991): Organizational Learning and Communities-of-Practice: Toward a unified View of Working, Learning and Innovation. Organizational Science, 2 (1991) 1, pp. 40-57.

Burt, R. (1979): A structural theory of interlocking corporate directorates. In: Social Networks, 2, pp. 415-435.

Davenport, T. (1993): Process-Innovation - Reengineering Work through Information Technology. Harvard Business School Press. Boston.

Drucker, P. F. ( 1989): The new realities. Harper Business. New York.

Giddens, A. (1991): Structuration theory: past, present and future. In: Bryant, C.G.A./ Jary, D. (Eds.): Giddens 'theory of structuration. A critical appreciation. London, New York, pp. 201221.

Hammer, M./ Champy, J. (1993): Reengineering the Corporation. Harper Business. New York.

Keen, P. (1991): Shaping the future: business design through information technology. Harvard Business School Press. Boston.

Kelly, G. A. (1955): The psychology of personal constructs. Norton. New York.

Krackhardt, D./ Hanson, J. R. (1997): Informal Networks: The Company. In: Prusak, L. (Ed.): Knowledge in Organizations. Butterworth-Heinemann. Boston, pp. 37-49.

Krebs, M./ Rock, R. (1994): Unternehmensnetzwerke ein intermediäre oder eigenständige Organisationsform. In: Sydow, J./ Windeler, A. (Eds.): Management interorganisationaler Beziehungen. Vertrauen, Kontrolle und Informationstechnik. Westdeutscher Verlag. Opladen. 
Lamb, J. (1990): Europe`s grand alliances. In: Datamation, 36, pp. 81-83.

Lincoln, J. R. (1982): Intra- (and inter-) organizational networks. In: Bacharach, S. B. (Ed.): Research in the sociology of organizations. JAI. Greenwich. Conneticut, pp. 255-294.

Lodge, G. C./ Walton, R. E. (1989): The American corporation and ist new relationships. In: California Management Review, 31, pp. 9-24.

Luhmann, N. (1988): Die Wirtschaft der Gesellschaft. Suhrkamp. Frankfurt.

Mayer, U./ Paasch, U. (1987): Deregulierung von Arbeitsbedingungen durch selbständige Beschäftigung. In: WSI-Mitteilungen, 40, pp. 581-589.

Mayer, U./ Paasch, U. (1990): Ein Schein von Selbständigkeit. Bund, Köln.

Mitchell, J. C. (1969): The concept and use of social networks: In: Michtell, J. C. (Ed.): Social networks in urban situations. Manchester University Press. Manchester, pp. 1-12.

Morgan, G. (1986): Images of organizations. Sage. Beverly Hills.

Morris, J./ Imrie, R. (1991): Transformation in the buyer-supplier relationship. Macmilian. London.

Müller-Hagedorn, L. (1990): Zur Erklärung der Vielfalt und Dynamik der Vertriebsformen. In: Zeitschrift für betriebswirtschaftliche Forschung, 6, pp. 451-466.

Nolan, R./ Pollock, A. J./ Ware, J. P. (1988): Creating the $21^{\text {st }}$ Century Organization. In: Stage by Stage, 4, pp. 4-11.

Nonaka I. (1991): The Knowledge Creating Company. In: Harvard Business Review, 6, pp. 96-104.

Nonaka, I. (1999): Leading Knowledge Creation. Plenary Speech at 32nd Hawaii International Conference on System Sciences, 05.-08.01.1999, Maui, Hawaii.

Nonaka, I./ Konno, N. (1998): The Concept of "Ba": Building a Foundation for Knowledge Creation. In: California Management Review, 40, pp. 40-55.

Nonaka, I./ Reinmoeller, P./ Senoo, D. (1998): The Art of Knowledge: Systems to Capitalize on Market Knowledge. In: European Management Journal, 16, pp. 673-684.

Nonaka, I./ Takeuchi I. (1995): The Knowledge Creating Company. How Japanese Companies cretae the dynamics of innovation. Oxford University Press. New York/ Oxford.

Orlikowski, W. (1992): The Duality of Technology: Rethinking the Concept of Technology in Organizations. In: Organization Science, 3, pp. 398-427.

Paasch, U. (1990): „Selbstfahrende Unternehmer“ - oder: Wie der Traum von der Selbständigkeit unter die Räder kommt. In: WSI-Mitteilungen, 43, pp. 220-227.

Pisano, G. P./ Russo, M. V./ Teece, D. J. (1988): Joint ventures and collaborative arrangements in the telecommunications equipment industry. In: Mowrey, D. C. (Ed.) International collaborative ventures in U.S. manufacturing. Ballinger. Cambridge, Mass., pp. 23-70.

Powell, W. (1990): Neither market nor hierarchy: Networks forms of organization: In: Staw, B. M./ Cummings, L. L. (Ed.) Research in organizational behavior. Vol 12. JAI. Greenwich, Conneticut, pp. 295-336. 
Powell, W./ Koput, K./ Smith-Doerr, L. (1996): Interorganizational Collaboration and the Locus of Innovation: Networks of Learning in Biotechnology. In: Administrative Science Quarterly, 41 (1996), pp. 116-145.

Probst, G. J. B. (1987): Selbstorganisation. Parey. Hamburg.

Reich, R. B. (1991): The work of Nations: Preparing ourselves for the $21^{\text {st }}$-Century Capitalism. Knopf. New York.

Sabel, C. F./ Kern, H./ Herrigel, G. (1991): Kooperative Produktion. In: Mendius, H. G./ Wendling-Schröder, U. (Eds.): Zulieferer im Netz - Zwischen Abhängigkeit und Partnerschaft. Bund. Köln, pp. 203-227.

Sandner, K. (1990): Prozesse der Macht. Springer. Berlin/ New York.

Savage Ch. (1990): Fifth Generation Management. Integrating enterprises through human networking. Digital Press. Bedford.

Seufert A. (1997): Groupware-enabled Data Warehouse. Management Support für die professionelle Know-how Organisation Prüfungs- und Beratungsgesellschaft. Dissertation thesis. University of St. Gallen.

Seufert, A./ Seufert S. (1998a): Knowledge Creation and Transfer in Knowledge Networks. In: IO Management, 67, pp. 77-84.

Seufert, S./ Seufert A. (1998b): Collaborative Learning in an Inter-University Learning Network. In: Informatik/ Informatique, 5, pp. 14-20.

Seufert, S./ Seufert, A. (1999): The Genius Approach: Building Learning Networks for Advanced Management Education (mit Andreas Seufert). In: Proceedings 32nd Hawaii International Conference on System Sciences, 05.-08.01.1999, Maui, Hawaii.

Siebert, H. (1991): Ökonomische Analyse von Unternehmungsnetzwerken. In: Staehle, W. H./ Sydow, J. (Eds.): Managementforschung 1. DeGruyter. Berlin/ New York, pp. 291-311.

Sydow, J. (1992): Strategische Netzwerke. Evolution und Organisation. Gabler. Wiesbaden.

Sydow, J./ Windeler, A./ Krebs, M./ Loose, A./ van Well, B. (1995): Organisation von Netzwerken. Strukturationstheoretische Analysen der Vermittlungspraxis in Versicherungsnetzwerken. Westdeutscher Verlag. Opladen.

Thorelli, H. B. (1986): Networks: Between markets and hierarchies. In: Sloan Management Review, 7, pp. 37-51.

Tichy, N./ Tushman, M./ Fombrun, C. (1979): Social networks analysis for organizations. In: Academy of Management Review, 4, pp. 507-519.

Von Krogh, G. (1998): Care in Knowledge Creation. In: California Management Review, 40, pp. 133-153.

Von Krogh, G./ Köhne, M. (1998): Der Wissenstransfer in Unternehmen: Phasen des Wissenstransfers und wichtige Einflussfaktoren. In: Die Unternehmung, 6, pp. 235-252.

Von Krogh, G./ Nonaka, I./ Ichijo K. (1997): Develop Knowledge Activists !. In: European Management Journal, 15, pp. 475-483. 
Von Krogh, G./ Venzin, M. (1996): Anhaltende Wettbewerbsvorteile durch Wissensmanagement. In: Die Unternehmung, 49, pp. 417-436.

Walker, G. (1985): Network position and cognition in a computer software firm. In: Administrative Science Quarterly, 30, pp. 103-130.

Webster, F. E. (1992): The Changing Role of Marketing in the Corporation. In: Journal of Marketing, 56, pp. 1-17.

Weisenfeld, U./ Chakrabari, A. K. (1990): Technologie und Marketingstrategien in der Biotechnologie: Ergebnisse einer deutschen und amerikanischen Studie. In: Die Betriebswirtschaft, 50, pp. 747-758. 